ISSN : $2338-4794$

Vol. 6. No. 3. September-Desember 2018

\title{
PENGARUH KUALITAS LAYANAN TERHADAP KEPUASAN NASABAH
}

\author{
Ismail Razak ${ }^{1)}$ \\ 1) Dosen Program Studi Manajemen FE-UNKRIS \\ Email: ismailrazak.zain@gmail.com \\ Rasmansyah $^{2}$ \\ 2) Dosen Program Studi Manajemen FE-UNKRIS \\ Alamat: Kampus UNKRIS, Jatiwaringin Jakarta Timur \\ Email: ismailrazak.zain@gmail.com \\ Email: rasmansyah31@gmail.com
}

\begin{abstract}
The aim of this study was to analize the influence of services quality indicators on the satisfaction of customers. Primary data was obtained from customers of Bank BNI Pondok Gede Plaza, Bekasi City through admission filling of questionnaire by using scale of Likert. In this study is used purposive sampling method. Data analysis technique used in this research is simple linear regression and multiple linear regression. The results of this study indicated that tangible, reliability, responsiveness, assurance, and emphaty positively and significant influenced the satisfaction of customers. The conclution of this study is that reliability was dominant than the other service quality indicators in influencing the satisfaction of customers.
\end{abstract}

Keywords: Service quality, tangible, reliability, responsiveness, assurance, emphaty, and satisfaction of customers. 


\section{PENDAHULUAN}

Kualitas layanan merupakan salah satu faktor penting dalam bisnis perbankan dalam upaya meningkatkan kepuasan nasabah, artinya layanan semakin berkualitas dapat mendorong nasabah semakin puas. Persaingan dalam bisnis perbankan semakin ketat, dimana setiap bank memiliki banyak pilihan layanan yang beragam dalam upaya mendorong terciptanya kepuasan nasabah. Menurut Samli dan Frohlich (1992), memberikan layanan berkualitas kepada pelanggan adalah suatu keharusan untuk sukses dan bertahan hidup di lingkungan perbankan yang kompetitif saat ini (Quyet, et al; 2015). Hal ini sejalan dengan yang dikatakan oleh Sasongko dan Subagio (2013), kualitas layanan memiliki hubungan yang erat dengan kepuasan pelanggan, sedangkan Darmawan, et al (2017), kualitas layanan telah menjadi alat utama untuk mengetahui tingkat kepuasan pelanggan.

Banyak hasil penelitian mengenai perbankan yang telah dipublikasikan yang menjelaskan hubungan kausalitas antara kualitas layanan dengan kepuasan nasabah, seperti penelitian yang dilakukan oleh Kuswanto (2009), Manusamy et al (2010), Anand dan Selvaraj (2012), Pontoh et, al (2014), Sondakh (2014), Rahayu dan Saryanti (2014), Shah, et al (2015), Mulyaningsih dan Suasana (2016), Hennayake (2017), dan Fellix (2017).

Bank Negara Indonesia, yang saat ini lebih dikenal dengan sebutan Bank BNI adalah Badan Usaha Milik Negara (BUMN). Bank Negara Indonesia merupakan bank komersial tertua dalam sejarah Republik
Indonesia. Bank Negara Indonesia didirikan pada tanggal 5 Juli 1946 menjadi Bank Sirkulasi atau Bank Sentral yang bertanggung jawab menerbitkan dan mengelola mata uang Republik Indonesia. Beberapa bulan setelah pendiriannya, Bank Negara Indonesia mulai mengedarkan alat pembayaran resmi pertama, yaitu Oeang Republik Indonesia atau ORI.

Pada tahun 1955, Bank Negara Indonesia berperan menjadi bank pembangunan, dan dalam perkembangan selanjutnya bertindak sebagai bank devisa. Sejalan dengan penambahan modal pada tahun 1955, status Bank Negara Indonesia beralih menjadi bank umum dengan penetapan secara yuridis melalui Undang-Undang Darurat nomor 2 tahun 1955. Dengan inovasi perbankan yang luas, menimbulkan kepercayaan pemerintah terhadap Bank Negara Indonesia, sehingga pada tahun 1968, status hukum Bank Negara Indonesia ditingkatkan menjadi persero dengan nama PT Bank Negara Indonesia. Mejelang akhir tahun 2015, PT. Bank Negara Indonesia mendapat izin beroperasi di Myanmar dengan membuka kantor cabang yang akan dibantu kantor cabang Singapura untuk menggarap segmen korporasi dan memberikan layanan remitansi bagi para staf kedutaan besar Republik Indonesia (KBRI). Saat ini, Bank BNI mempunyai 914 kantor cabang di Indonesia dan 5 kantor cabang di luar negeri. Bank BNI juga mempunyai unit perbankan syariah, namun sejak tahun 2010 telah memisahkan diri (spin off), yang dinamakan Bank BNI Syariah. Bank BNI terpilih dan dipercaya menjadi bank yang melayani pembayaran bagi para 
investor asing yang ingin menanamkan modalnya di Indonesia. Berdasarkan penjelasan tersebut, tujuan penelitian ini adalah untuk menganalisis pengaruh indikator kualitas layanan yang terdiri atas indikator bukti fisik, kehandalan, daya tanggap, jaminan, dan empati terhadap kepuasan nasabah baik secara parsial maupun secara bersama-sama. Hasil penelitian ini diharapkan bermanfaat bagi semua pihak. Bagi penelitian berikutnya diharapkan hasil penelitian ini bermanfaat sebagai referensi, sedangkan bagi pimpinan bank diharapkan hasil penelitian ini bermanfaat sebagai masukan di dalam menetapkan strategi mengenai peningkatan kepuasan nasabah.

\section{LANDASAN TEORI}

\section{Kualitas layanan}

Layanan yang berkualitas menunjukkan keunggulan suatu layanan yang ditawarkan kepada pelanggan. Kualitas layanan lebih menekankan pada kualitas proses, karena pelanggan biasanya terlibat langsung dalam proses tersebut (Yamit, 2013). Para ahli mendefinisikan kualitas sebagai kecocokan dengan selera pelanggan atau kesesuaian dengan kebutuhan dan persyaratan pelanggan. Kotler dan Keller (2012), kualitas (quality) adalah totalitas fitur dan karakteristik produk atau jasa yang bergantung pada kemampuannya untuk memuaskan kebutuhan yang dinyatakan atau tersirat. Smith (1988) mendefinisikan kualitas layanan sebagai memenuhi kebutuhan dan harapan pelanggan (Nautiyal; 2014), sedangkan Atiyah (2017) mengatakan bahwa kualitas layanan adalah kemampuan organisasi untuk memberikan layanan kepada pelanggan secara akurat dan tepat dan sangat andal bagi pelanggan. Susepti, et al (2017), kualitas layanan adalah tingkat keunggulan yang diharapkan dan pengendalian atas tingkat keunggulan tersebut untuk memenuhi keinginan pelanggan.

Berdasarkan pengertian tersebut, menunjukkan bahwa kualitas layanan merupakan keunggulan layanan yang ditawarkan perusahaan berdasarkan kecocokan dengan selera pelanggan atau adanya kesesuaian dengan kebutuhan dan persyaratan pelanggan. Layanan yang berkualitas dipersepsikan oleh pelanggan sebagai layanan yang dirasakan (perceived service) sesuai dengan layanan yang diharapkan (expected service), sehingga kepuasan pelanggan terpenuhi. Sebaliknya, layanan yang tidak berkualitas dipersepsikan pelanggan sebagai layanan yang dirasakan tidak sesuai dengan layanan yang diharapkan, sehingga kepuasan pelanggan tidak terpenuhi. Dengan demikian, terpenuhi atau tidak terpenuhi harapan pelanggan, tergantung kepada kemampuan perusahaan didalam menawarkan kualitas layanan yang dirasakan pelanggan.

Parasuraman, et al (1985) mengidentifikasi lima dimensi yang disebut servqual, yaitu bukti fisik (tangible), kehandalan (reliability), daya tanggap (responsiveness), jaminan (assurance), dan empati (emphaty) (Heri, 2017)). Bukti fisik meliputi fasilitas fisik (gedung dan tata letak ruangan), tersedianya tempat parkir, kebersihan dan kenyamanan ruangan, perlengkapan, 
personal, kelengkapan sarana komunikasi, penampilan karyawan. Kehandalan, yaitu kemampuan untuk memberikan layanan sesuai dengan yang dijanjikan, seperti memberikan informasi yang diperlukan secara tepat, melayani transaksi dengan cepat, melayani setiap pengaduan dengan cepat, dan membantu untuk menyelesaikan masalah. Daya tanggap, yaitu kesediaan para karyawan untuk membantu para pelanggan dan memberikan layanan yang cepat dan tanggap, meliputi kesigapan melayani pelanggan, sigap memberikan informasi yang diperlukan, dan sigap dalam menangani berbagai keluhan pelanggan. Jaminan, yaitu mencakup jaminan keamanan, jaminan layanan tidak mengada-ngada, dan jaminan kemampuan dalam menanamkan kepercayaan pelanggan terhadap perusahaan. Empati, yaitu perhatian yang diberikan perusahaan kepada pelanggan, meliputi menghargai pelanggan, ramah, sopan, kemudahan untuk menghubungi perusahaan, komunikasi yang baik, dan perhatian dengan tulus terhadap kebutuhan pelanggan (Yamit, 2013; Sasongko dan Subagio, 2013; Nautiyal, 2014; Heri, 2017; Windarti dan Ibrahim, 2017).

\section{Kepuasan Pelanggan}

Kotler dan Keller (2012) mengatakan bahwa kepuasan adalah perasaan senang atau kecewa seseorang yang muncul setelah membandingkan antara persepsi atau kesan terhadap kinerja atau hasil suatu produk dan harapan-harapan. Heri (2017), kepuasan sebagai tanggapan pelanggan mengenai evaluasi persepsi ketidaksesuaian antara harapan sebelumnya dan kinerja aktual dari produk setelah dikonsumsi, sedangkan Darmawan, et al (2017), kepuasan telah didefinisikan sebagai tingkat reaksi emosional dari pengalaman layanan. Dengan demikian, kepuasan didasarkan pada pengalaman langsung di masa lalu.

Kepuasan pelanggan menurut Jahanshahi, et al (2011) adalah hasil persepsi pelanggan dari nilai yang diterima dalam transaksi atau hubungan - dimana nilai sama dengan persepsi kualitas layanan relatif terhadap harga dan biaya akuisisi pelanggan, sedangkan menurut Schiffman dan Kanuk (2004), kepuasan pelanggan adalah persepsi individu terhadap kinerja suatu barang atau jasa dikaitkan dengan harapan pelanggan tersebut. Zeithaml dan Bitner (2005), kepuasan pelanggan adalah evaluasi pelanggan mengenai suatu barang dan jasa yang dibutuhkan dan diharapkan pelanggan (Sangadji dan Sopiah, 2013). Kotler dan Amstrong (2012) mengatakan bahwa kepuasan pelanggan adalah sejauh mana kinerja yang dirasakan suatu produk sesuai harapan pembeli. Berbeda dengan pendapat $\mathrm{Tu}$, et al., (2013), yang mengatakan bahwa kepuasan pelanggan dipandang sebagai yang mempengaruhi niat pembelian kembali dan perilaku, yang mana, pada giliran, menyebabkan pendapatan dan keuntungan organisasi di masa depan.

Berarti, kepuasan pelanggan merupakan hasil evaluasi pelanggan terhadap layanan setelah dikonsumsi yang memberikan tingkat kepuasan tertentu. Mengukur kepuasan pelanggan, yaitu melihat seberapa besar harapan pelanggan dapat terpenuhi dibandingkan dengan 
manfaat layanan yang dapat memenuhi kebutuhan dan keinginan pelanggan. Menurut Kotler dan Keller (2012), pelanggan yang merasa puas akan tetap setia untuk waktu lama, membeli lagi ketika perusahaan memperkenalkan produk baru dan memperbarui produk lama, membicarakan hal-hal baik tentang perusahaan dan produk kepada orang lain, dan keluhan pelanggan. Usaha untuk memuaskan pelanggan harus dilakukan secara saling menguntungkan baik bagi pelanggan maupun perusahaan.

\section{Hipotesis}

1. Bukti fisik berpengaruh positif dan signifikan terhadap kepuasan nasabah.

2. Kehandalan berpengaruh positif dan signifikan terhadap kepuasan nasabah.

3. Daya tanggap berpengaruh positif dan signifikan terhadap kepuasan nasabah.

4. Jaminan berpengaruh positif dan signifikan terhadap kepuasan nasabah.

5. Empati berpengaruh positif dan signifikan terhadap kepuasan nasabah.

6. Bukti fisik, kehandalan, daya tanggap, jaminan, dan empati secara bersama-sama berpengaruh positif dan signifikan terhadap kepuasan nasabah.

\section{METODE PENELITIAN}

\section{Rancangan Penelitian}

Penelitian ini dirancang untuk menjelaskan hubungan kausalitas antara indikator kualitas layanan, yang terdiri atas bukti fisik, kehandalan, daya tanggap, jaminan, dan empati dengan kepuasan nasabah melalui pengujian hipotesis. Penelitian ini merupakan studi kasus. Tujuan penelitian yang menjelaskan hubungan kausalitas ini adalah untuk menganalisis pengaruh bukti fisik, kehandalan, daya tanggap, jaminan, dan empati dengan kepuasan nasabah. Data yang digunakan dalam penelitian ini merupakan data primer melalui pengisian kuesioner kepada para nasabah Bank BNI. Metode analisis yang digunakan adalah metode analisis regresi linear sederhana dan regresi linear berganda.

\section{Metode Pengumpulan Data}

Penelitian ini dilakukan di Bank BNI Pondok Gede Plaza di Kota Bekasi. Data yang dikumpulkan adalah data primer yang diperoleh dari para nasabah Bank BNI Pondok Gede Plaza, di Kota Bekasi melalui pengisian daftar pertanyaan (kuesioner) dengan menggunakan Skala Likert. Skala Likert yang digunakan adalah sangat setuju dengan bobot 5 , setuju dengan bobot 4 , netral dengan bobot 3, tidak setuju dengan bobot 2 , dan sangat tidak setuju dengan bobot 1 .

Populasi dalam penelitian ini adalah seluruh nasabah Bank BNI Pondok Gede Plaza, Kota Bekasi. Populasi dalam penelitian ini tidak dapat diketahui dengan pasti, karena Bank BNI Pondok Gede Plaza, Kota Bekasi tidak bersedia untuk memberikan jumlah nasabah, sehingga pengambilan sampel menggunakan sampel nonprobabilitas (non-probability sampling), yaitu purposive sampling. Sampel non-probabilitas dipilih karena masing-masing anggota 
populasi tidak diketahui dan tidak ada upaya untuk melakukan generalisasi berdasarkan sampel, serta masalah representasi (keterwakilan) tidak dipersoalkan (Kuncoro, 2003). Purposive sampling digunakan dalam penelitian ini dengan pertimbangan responden pernah datang dan melakukan transaksi lebih dari satu kali di Bank BNI Pondok Gede Plaza, Kota Bekasi dalam 3 bulan terakhir dan minimal telah berusia 17 tahun, serta bersedia mengisi kuesioner dengan benar. Penelitian dilaksanakan selama 3 bulan, yaitu bulan Februari hingga April tahun 2018 melalui pengisian kuesioner kepada nasabah sebagai responden yang pernah datang ke Bank BNI Pondok Gede Plaza, Kota Bekasi, dan diperolah 84 responden. Jumlah sampel sebanyak ini dapat mewakili populasi nasabah, seperti yang dinyatakan oleh Sakaran (2003), bahwa jumlah sampel lebih besar dari 30 dan kurang dari 500 responden dianggap memenuhi syarat.

\section{Metode Analisis Data}

Untuk menganalisis pengaruh indikator kualitas layanan terhadap kepuasan nasabah Bank BNI secara sendiri-sendiri digunakan metode analisis regresi linear sederhana (simple linear regression), yaitu sebagai berikut;

$$
\mathrm{Y}=\alpha+\beta_{\mathrm{i}} \mathrm{X}_{\mathrm{i}}
$$

Untuk menganalisis pengaruh indikator kualitas layanan terhadap kepuasan nasabah Bank BNI secara bersama-sama digunakan metode analisis regresi linear berganda (multiple linear regression), yaitu sebagai berikut;

$$
Y=\alpha+\beta_{1} X_{1}+\beta_{2} X_{2}+\beta_{3} X_{3}+\beta_{4} X_{4}+\beta_{5} X_{5}
$$

di mana;

$$
\mathrm{Y}=\text { Kepuasan nasabah }
$$$$
\mathrm{X}_{\mathrm{i}}=(\mathrm{i}=1,2, \ldots . .5)
$$

$\mathrm{X}_{1}=$ Bukti fisik

$\mathrm{X}_{2}=$ Kehandalan

$\mathrm{X}_{3}=$ Daya tanggap

$\mathrm{X}_{4}=$ Jaminan

$\mathrm{X}_{5}=$ Empati

$\alpha=$ Konstanta

$\beta_{\mathrm{i}}=$ Koefisien regresi $(\mathrm{i}=1,2, \ldots .5)$

\section{HASIL DAN PEMBAHASAN}

\section{Hasil Penelitian}

\section{Uji Validitas dan Reliabilitas}

Variabel penelitian kualitas layanan yang terdiri dari berbagai indikator, terdiri atas bukti fisik, kehandalan, daya tanggap, jaminan, dan empati, serta kepuasan nasabah memiliki 24 butir pertanyaan berupa pernyataan. Hasil pengujian menunjukkan bahwa 24 butir pertanyaan dinyatakan valid dan reliabel, artinya bahwa responden telah memahami setiap pertanyaan yang diajukan dan responden konsisten pada butir pertanyaan yang ditentukan.

\section{Hasil Uji Hipotesis}

Hipotesis menunjukkan bahwa seluruh jalur secara parsial dalam persamaan regresi linear sederhana berpengaruh positif dan signifikan ( $p$ value atau nilai probabilitas $<0,05$ ), sedangkan secara bersama-sama dalam persamaan regresi linear berganda tidak semua jalur berpengaruh positif dan signifikan ( $p$ value atau nilai probabilitas $<0,05)$. 
Tabel-1: Pengaruh Kualitas layanan terhadap Kepuasan Pelanggan

\begin{tabular}{|c|c|c|c|c|c|c|}
\hline \multirow{2}{*}{$\begin{array}{c}\text { Variabel } \\
\text { Independen }\end{array}$} & \multicolumn{5}{|c|}{ Koefisien Regresi } & \multirow[b]{2}{*}{ Hipotesis-6 } \\
\hline & Hipotesis-1 & Hipotesis-2 & Hipotesis-3 & Hipotesis-4 & Hipotesis-5 & \\
\hline Konstanta & $\begin{array}{c}25,431^{* * * * *} \\
(0,000)\end{array}$ & $\begin{array}{c}15,812^{* * * * *} \\
(0,000)\end{array}$ & $\begin{array}{c}20,415^{* * * *} \\
(0,000)\end{array}$ & $\begin{array}{c}22,781^{\text {****** }}(0,000) \\
\end{array}$ & $\begin{array}{c}24,596^{* * * *} \\
(0,000)\end{array}$ & $\begin{array}{c}15,456^{\text {***** }} \\
(0,000)\end{array}$ \\
\hline Bukti fisik $\left(X_{1}\right)$ & $\begin{array}{c}0.847^{* * * *} \\
(0,005)\end{array}$ & - & - & - & - & $\begin{array}{c}0,224 \\
(0,451)\end{array}$ \\
\hline Kehandalan $\left(\mathrm{X}_{2}\right)$ & - & $\begin{array}{l}1,661^{* * * *} \\
(0,000)\end{array}$ & - & - & - & $\begin{array}{l}1,612^{\text {**** }} \\
(0,000)\end{array}$ \\
\hline Daya Tanggap $\left(\mathrm{X}_{3}\right)$ & - & - & $\begin{array}{l}1,300^{* * * *} \\
(0,000)\end{array}$ & - & - & $\begin{array}{c}0,017 \\
(0,971)\end{array}$ \\
\hline Jaminan $\left(\mathrm{X}_{4}\right)$ & - & - & - & $\begin{array}{l}1,019^{* * * *} \\
(0,000)\end{array}$ & - & $\begin{array}{c}0,517 \\
(0,066)\end{array}$ \\
\hline Empati $\left(\mathrm{X}_{5}\right)$ & - & - & - & - & $\begin{array}{c}0,880^{* * * *} \\
(0,009)\end{array}$ & $\begin{array}{c}-0,676 \\
(0,098)\end{array}$ \\
\hline $\mathrm{F}_{\text {-hitung }}$ & - & - & - & - & - & $9,368^{* * * *}$ \\
\hline $\mathrm{R}^{2}$ & 0,088 & 0,319 & 0,164 & 0,186 & 0,078 & 0,369 \\
\hline
\end{tabular}

Hasil analisis menunjukkan bahwa estimasi berdasarkan hipotesis-1 hingga hipotesis-5, koefisien determinasi $\left(\mathrm{R}^{2}\right)$ berkisar antara 0,078 hingga 0,319 . Hal ini menunjukkan bahwa koefisien determinasi terendah adalah empati, yaitu sebesar 0,078, artinya empati memberikan konstribusi kepada kepuasan nasabah Bank BNI sebesar $7,8 \%$, sedangkan sisanya sebesar 92,2\% disumbangkan oleh faktor kualitas layanan lainnya, seperti bukti fisik, kehandalan, daya tanggap, dan jaminan. Koefisien determinasi tertinggi adalah kehandalan, yaitu sebesar 0,319 , artinya kehandalan memberikan konstribusi kepada kepuasan nasabah Bank BNI sebesar 31,9\%, sedangkan sisanya sebesar $68,1 \%$ disumbangkan oleh faktor kualitas layanan lainnya, seperti bukti fisik, daya tanggap, jaminan, dan empati.

Hasil analisis menunjukkan bahwa estimasi koefisien regresi secara parsial bukti fisik, kehandalan, daya tanggap, jaminan, dan empati dalam hipotesis-1 hingga hipotesis-5, masing-masing bertanda positif dan signifikan pada tingkat nyata $99 \%$ terhadap kepuasan nasabah Bank BNI, sesuai dengan hipotesis. Tanda positif menunjukkan bahwa jika ada perbaikan masing-masing dari bukti fisik, kehandalan, daya tanggap, jaminan, dan empati, maka kepuasan nasabah Bank BNI diduga meningkat atau sebaliknya. Koefisien regresi berkisar antara 0,847 hingga 1,661. Hal ini menunjukkan bahwa koefisien regresi terendah adalah bukti fisik, yaitu sebesar 0,847 , artinya jika ada perbaikan bukti fisik sebesar satu kali, maka kepuasan nasabah Bank BNI diduga akan meningkat sebesar 0,847 kali atau sebaliknya. Koefisien regresi tertinggi adalah kehandalan, yaitu sebesar 1,661, artinya jika ada perbaikan kehandalan sebesar satu kali, maka kepuasan nasabah Bank BNI diduga akan meningkat sebesar 1,661 kali atau sebaliknya. 
Berdasarkan Hipotesis-6, F. hitung sebesar 9,368, artinya bukti fisik, kehandalan, daya tanggap, jaminan, dan empati secara bersamasama berpengaruh signifikan pada tingkat nyata $99 \%$ terhadap kepuasan nasabah Bank BNI, dengan koefisien determinasi $\left(\mathrm{R}^{2}\right)$ sebesar 0,369 , yang artinya bukti fisik, kehandalan, daya tanggap, jaminan, dan empati secara bersama-sama memberikan kontribusi kepada kepuasan nasabah Bank BNI sebesar 36,9\%, sedangkan sisanya sebesar 63,1\% disumbangkan oleh faktor lainnya, seperti citra perusahaan, promosi, dan sebagainya.

Koefisien regresi kehandalan bertanda positif dan signifikan pada tingkat nyata $99 \%$, sedangkan empati bertanda negatif dan tidak signifikan. Bukti fisik, daya tanggap, dan jaminan bertanda positif dan tidak signifikan terhadap kepuasan nasabah Bank BNI. Tanda positif menunjukkan bahwa jika ada perbaikan bukti fisik, kehandalan, daya tanggap, atau jaminan, maka kepuasan nasabah Bank BNI diduga akan meningkat. Koefisien regresi yang bertanda positif berkisar antara 0,017 hingga 1,612. Hal ini menunjukkan bahwa koefisien regresi terendah adalah daya tanggap, yaitu sebesar 0,017, artinya jika ada perbaikan daya tanggap sebesar satu kali, maka kepuasan nasabah Bank BNI diduga akan meningkat sebesar 0,017 kali dengan asumsi faktor lain, seperti bukti fisik, kehandalan, jaminan, dan empati tidak berubah (konstan), atau sebaliknya. Koefisien regresi tertinggi adalah kehandalan, yaitu sebesar 1,612, artinya jika ada perbaikan kehandalan sebesar satu kali, maka kepuasan nasabah Bank BNI diduga akan meningkat sebesar 1,612 kali dengan asumsi faktor lain, seperti bukti fisik, daya tanggap, jaminan, dan empati tidak berubah (konstan), atau sebaliknya.

\section{Pembahasan}

Peningkatan kualitas layanan melalui perbaikan bukti fisik menunjukkan bahwa tersedia tempat parkir yang luas, ruang tunggu yang nyaman, dan karyawan berpenampilan rapi dapat mendorong meningkatkan kepuasan nasabah agar tetap setia, bersedia merekomendasikan, dan kecil hasrat mengajukan keluhan. Peningkatan kualitas layanan melalui perbaikan keandalan menunjukkan bahwa nasabah mudah mendapatkan informasi yang diperlukan secara cepat, melayani transaksi dengan cepat, dan melayani setiap pengaduan dengan cepat dapat mendorong meningkatkan kepuasan nasabah agar tetap setia, bersedia merekomendasikan, dan kecil hasrat mengajukan keluhan. Peningkatan kualitas layanan melalui perbaikan daya tanggap menunjukkan bahwa karyawan sigap menerima setiap keluhan nasabah, karyawan sigap memberikan setiap informasi yang diperlukan nasabah, dan karyawan sigap melayani nasabah dapat mendorong meningkatkan kepuasan nasabah agar tetap setia, bersedia merekomendasikan, dan kecil hasrat mengajukan keluhan. Peningkatan kualitas layanan melalui perbaikan jaminan menunjukkan bahwa dijamin karyawan bisa dipercaya, dijamin keamanan dalam melakukan transaksi, dan dijamin layanan yang 
diberikan tidak mengada-ngada dapat mendorong meningkatkan kepuasan nasabah agar tetap setia, bersedia merekomendasikan, dan kecil hasrat mengajukan keluhan. Peningkatan kualitas layanan melalui perbaikan empati menunjukkan bahwa perhatian karyawan agar menghargai nasabah, perhatian karyawan agar tetap ramah kepada nasabah, dan perhatian karyawan agar mudah dihubungi oleh nasabah dapat mendorong meningkatkan kepuasan nasabah agar tetap setia, bersedia merekomendasikan, dan kecil hasrat mengajukan keluhan. Namun demikian, jika dilakukan secara bersama-sama, peningkaan kualitas layanan melalui empati menunjukkan bahwa perhatian karyawan agar menghargai nasabah, perhatian karyawan agar tetap ramah kepada nasabah, dan perhatian karyawan agar mudah dihubungi oleh nasabah ternyata belum dapat mendorong meningkatkan kepuasan nasabah agar tetap setia, bersedia merekomendasikan, dan kecil hasrat mengajukan keluhan..

Hasil penelitian ini sesuai dan memperkuat penelitian terdahulu mengenai perbankan yang dilakukan oleh Nautiyal (2014), Quyet, et al (2015), Al-Azzam (2015), Dawit dan Adem (2016), Bhatta dan Durgapal (2016), Toor, et al (2016), Pasha dan Razashah (2018), yang telah membuktikan bahwa kualitas layanan melalui perbaikan bukti fisik, kehandalan, daya tanggap, jaminan, dan empati dapat mendorong peningkatan kepuasan nasabah.

\section{Kesimpulan}

Secara sendiri-sendiri, setiap peningkatan kualitas layanan melalui perbaikan bukti fisik, kehandalan, daya tanggap, jaminan, dan empati dapat mendorong peningkatan kepuasan nasabah. Secara bersamasama, setiap peningkatan kualitas layanan melalui perbaikan bukti fisik, kehandalan, daya tanggap, dan jaminan dapat mendorong peningkatan kepuasan nasabah, sedangkan peningkatan kualitas layanan melalui perbaikan empati belum dapat mendorong peningkatan kepuasan nasabah. Kehandalan merupakan salah satu faktor kualitas layanan yang paling dominan di dalam mendorong peningkatan kepuasan nasabah, baik secara sendiri-sendiri maupun bersamasama.

\section{Saran}

Peningkatan kualitas layanan melalui perbaikan bukti fifik, kehandalan, daya tanggap, jaminan, tetap perlu dipertahankan dan jika perlu ditingkatkan lagi dalam upaya mendorong kepuasan nasabah, sedangkan peningkatan kualitas layanan melalui empati perlu banyak perbaikan untuk mendorong kepuasan nasabah. Perlu dipertimbangkan untuk dilakukan penelitian berikutnya dengan mempertimbangkan citra perusahaan sebagai variabel yang dapat mendorong peningkatan kepuasan nasabah. 


\section{DAFTAR PUSTAKA}

Agyapong, G. K. Q. 2011. The Effect of Service Quality on Customer Satisfaction in The Utility Industry-A Case Customer Satisfaction in The Utility Industry-A Case of Vodafone (Ghana). International Journal of Business and Management. Vol. 6, No. 5, May, 2011, 203-210.

Al-Azzam, A. F. M. 2015. The Impact of Service Quality Dimensions on Customer Satisfaction: A Field Study of Arab Bank in Irbid City. European Journal of Business and Management. Vol. 7, No. 15, 45-53.

Anand, S. V \& Selvaraj, M. 2012. The Impact of Service Quality on Customer Satisfaction and Loyalty in Indian Banking Sector: An Empirical Study through SERVPERF. International Journal Business Research. 2(2), Spring 2012, 151-163.

Aryani, D dan Rosinta, F. 2010. Pengaruh Kualitas Layanan terhadap Kepuasan Pelanggan dalam Membentuk Loyalitas Pelanggan. Jurnal Ilmu Administrasi dan Organisasi. Vol. 17, No. 2, Mei-Agustus 2010, 114-126.

Atiyah, L. A. 2017. Impact of Service Quality on Customer Satisfaction. Australian Journal of Basic and Applied Science. 11(5), April, pp.20-28.

Basith, A, Kumadji, S, dan Hidayat, K. 2014. Pengaruh Kualitas Produk dan Kualitas Pelayanan terhadap Kepuasan Pelanggan dan Loyalitas Pelanggan

(Survey pada Pelanggan

De'Pans Pancake and Waffe di

Kota Malang). Jurnal Administrasi Bisnis, Vol. 11, No. 1, Juni 2014.

Bhatta, K. R., \& Durgapal, B. P. 2016. Service Quality Perceptions and Customer Satisfaction in Nepalese Banking Sector. Indian Journal of Commerce \& Management Studies. Vol. VII, Issue 1, Jan, 17-23.

Bei, L. T \& Chiau, Y.C., 2001, "An Integrated Hipotesis for The Effects of Perceived Product, Perceived Service Quality, and Perceived Price Fairness on Consumer Satisfaction and Loyalty," Journal of Consumer Satisfaction, Dissatisfaction and Complaining Behavior, 14, 125140.

Darmawan, D., Mardikaningsih, R., dan Hadi, S. 2017. The Effect of Service Quality, Customer Satisfaction and Corporate Image on Customer Loyalty in the Banking Sector in Indonesia. Journal of Business and Management. Vol. 19, Issue 11, Ver. VI, November, 46-51.

Dawit, J. B., \& Adem, U. 2016. The Effect of Perceived Service Quality on Customer Satisfaction in Private Commercial Banks of Ethiopia: The Case of Selected Private Commercial Banks at Dire Dawa Administration. Business and Economics Journal. Vol. 9, Issue 2, 1-4.

Fathoni, S. A dan Haryono, A, T. 2016. Pengaruh Citra Perusahaan dan Kualitas 
Pelayanan terhadap Loyalitas Pelanggan dengan Kepuasan Pelanggan sebagai Variabel Intervening pada PT. Pelabuhan Indonesia III Semarang. Journal of Management, Vol. 2, Maret 2016, 1-16.

Fellix, R. 2017. Service Quality and Customer Satisfaction in Selected Banks in Rwanda. Journal Business \& Financial Affairs. 6;246, 1-11.

Haryanto, R, A. 2013. Strategi Promosi, Kualitas Produk, Kualitas Layanan terhadap Kepuasan Pelanggan pada Restoran McDonald's Manado. Jurnal EMBA, Vol. 1, No. 4, Desember 2013, 1465-1473.

Hennayake, H. M. G. Y. 2017. Impact of Service Quality on Customer Satisfaction of Public Sector Commercial Banks: A Study on Rural Economic Context. International Journal of Scientific and Research Publications. Vol. 7, Issue 2, February, 156-161.

Heri, H. 2017. Analysis the The Effect of Service Quality, Customer Value, Customer Satisfaction and Customer Trust on Corporate Image. 2017. Journal of Business and Management. Volume 19, Issue 6, Ver. 1, June, pp. 38-46.

$\mathrm{Hu}, \mathrm{K}, \mathrm{C}$ \& Huang, M. C. 2011. Effects of Service Quality, Innovation and Corporate Image on Customer's Satisfaction and Loyalty of Air Cargo Terminal. International Journal Operations Research. Vol. 8, No. 4, 36-47.

Iberahim, H., Taufik, M. N. K., Adzmir, M. A. S., \&
Saharuddin, H. 2016. Customer Satisfaction on Reliability and Responsiveness of Self Service Technology for Retail Banking Services. Procedia Economics and Finance 37, 13-20.

Irawan, H. 2008. Sepuluh Prinsip Kepuasan Pelanggan. Jakarta. Penerbit Elex Media Komputindo Kelompok Gramedia.

Jahanshahi, A.A, Gashti, M.A.H, Mirdamadi, S.A, Nawaser, K, \& Khaksar, S.M.S. 2011, Study of Effects of Customer Service and Product Quality on Customer Satisfaction and Loyalty. International Journal of Humanities and Social Science. Vol.1 No.7 (June), 253-260.

Kordnaeij, A., Askaripoor, H., \& Imani, A. 2013. The Impact of E-Banking Service Quality Dimensions on Customers Satisfaction and Brand Equity (Case Study: Refah Bank, Teheran). Business and Management Research, Vol. 2, No. 4, 25-37.

Kotler, P \& Amstrong, G. 2012, Principle of Marketing.14 Edition. New Jersey. Published by Prentice Hall.

Kotler, P \& Keller, K. L. 2012, Marketing Management. $14^{\text {th }}$ Edition. New Jersey. Published by Prentice Hall.

Kuncoro, M. 2003. Metode Riset untuk Bisnis \& Ekonomi. Jakarta. Penerbit Erlanga.

Kurniasih, N dan Razak, I. 2015. Pengaruh Faktor-faktor Kualitas Jasa terhadap Kepuasan Pelanggan Telkom Single Invoice di Kota Bekasi. Jurnal 
Transformasi, Vol. 10, No. 1, Februari 2015, 70-87.

Kuswanto, A. 2009. Pengaruh Kualitas Layanan terhadap Tingkat Kepuasan Nasabah. Jurnal Ekonomi Bisnis. Vol. 14, No. 2, Agustus2009.

Lupiyoadi, R. 2001. Manajemen Pemasaran Jasa; Teori dan Praktek. Jakarta. Salemba Empat.

Mardikawati, W dan Farida, N. 2013.

Pengaruh Nilai Pelanggan dan

Kualitas Layanan terhadap

Loyalitas Pelanggan Melalui

Kepuasan Pelanggan pada

Pelanggan Bus Efisiensi (Studi

PO Efisiensi Jurusan

Yogyakarta-Cilacap). Jurnal

Administrasi Bisnis, Vol. 2, No.

1, Maret 2013.

Markovic, S., Dorcie, J., \& Katusic,

G. 2015. Service Quality

Measurement in Croatian

Banking Sector: Application of

SERVQUAL Model.

Management International

Croatian Banking Sector:

Application of SERVQUAL

Model. Management

International Conference.

Portoroz, Slovenia,28-30 May, 209-218.

Mulyaningsih, L. A dan Suasana, I.

G. A. K, G. 2016. Pengaruh

Kualitas Layanan dan Citra

Persahaan terhadap Kepuasan

Nasabah pada Bank OCBC

NISP di Denpasar. Jurnal

Manajemen Unud. Vol. 5, No. 1, 2016, 1-30.

Mulyono, B. H, Yoestini, Nugraheni,

R, dan Kamal, M. 2007.

Analisis Pengaruh Kualitas

Produk dan Kualitas Layanan terhadap Kepuasan Konsumen
(Studi Kasus pada Perumahan Puri Mediterania Semarang). Jurnal Studi Manajemen \& Organisasi. Vol. 4, No. 2, Juli 2007.

Munusamy, J., Chelliah, S., \& Mun, H. W. 2010. Service Quality Delivery and Its Impact on Customer Satisfaction in Banking Sector in Malaysia. International Journal of Innovation, Management and Technology. Vol. 1, No. 4, October 2010, 398-404.

Nautiyal, G. 2014. Impact of Service Quality on Customer Satisfaction in the Retail Banking Sector. Global Journal of Commerce \& Management Perspective. Vol. 3 (3), MayJune, 77-80.

Pangandaheng, F. 2015. Pengaruh Kualitas Layanan dan Citra Perusahaan terhadap Kepuasan Pelanggan dan Dampaknya terhadap Loyalitas Pelanggan pada PT. Hadji Kalla Palu. Jurnal Katalogis. Vol. 3, No. 2, Pebruari 2015, 51-67.

Pasha, M. A., \& Razashah, M. 2018. Impact of Service Quality on Customer Satisfaction: An Empirical Study in Selected Public and Private Sector Banks. Journal of Arts, Science \& Commerce. Vol. IX, Issue 1, January, 64-73.

Pontoh, M. B., Kawet, L., dan Tumbuan, W, A. 2014. Kualitas Layanan, Citra Perusahaan dan Kepercayaan Pengaruhnya terhadap Nasabah Bank BRI Cabang Manado. Jurnal EMBA. Vol. 2, No. 3, September 2014, 285-297. 
Quyet, T. V, Vinh, N, Q, and Chang, T, 2015. Service Quality Effects on Customer Satisfaction in Banking Industry. Service, Science and Technology. Vol. 8, No.8, pp. 199-206.

Rahayu, B. S., dan Saryanti, E. 2014. Pengaruh Kualitas Pelayanan, Hubungan Pelanggan dan Citra Perusahaan terhadap Loyalitas Melalui Kepuasan Nasabah. Jurnal Advance. Vol. 1, No. 2, Pebruari 2014, 11-25.

Razak, I. 2014. Manajemen Pemasaran. Cetakan ke-3. Surabaya. Penerbit CV. Perwira Media Nusantara. , Junaidi, A, \& Hakim, L. 2012. Metodologi Penelitian Ekonomi dan Bisnis. Jakarta. Prenada Media Group.

Sachro \& Pudjiastuti, S. R. 2013. The Effect Service Quality to Customer Satisfaction and Customer Loyalty of Argo Bromo Anggrek Train JakartaSurabaya in Indonesia. Journal of Business and Management. Vol. 12, Issue 1, July-August 2013, 33-38.

Safitri, E, Rahayu, M, dan Indrawati, N. K. 2018. Pengaruh Kualitas Pelayanan dan Citra Perusahaan terhadap Kepuasan Pelanggan dan Loyalitas Pelanggan Service Center (Studi pada Pelanggan Samsung Service Center di Kota Malang). Jurnal Ekonomi Bisnis, Tahun 21, Nomor 1, Maret 2018, 90-104.

Saidani, B dan Arifin, S. 2012. Pengaruh Kualitas Produk dan Kualitas Layanan terhadap Kepuasan Konsumen dan Minat Beli pada Ranch Market. Jurnal
Riset Manajemen Sains Indonesia, Vol. 3, No. 1, 2012. Sakaran., U, 2003, Research Method for Business, $4^{\text {th }}$ edition, New York, John Wiley \& Sons Inc.

Saktiani, G. A, 2015. Pengaruh Kualitas Layanan dan Citra Perusahaan terhadap Kepuasan Pelanggan dan Word of Mouth. Jurnal Ilmu Sosial dan Ilmu Politik. Vol. 4 No. 2, 342-353.

Sangadji, E.M dan Sopiah. 2013. Perilaku Pelanggan. Yogyakarta. Andi.

Sasongko, F dan Subagio, H. 2013. Pengaruh Kepuasan Layanan terhadap Kepuasan Pelanggan Restoran Ayam Penyet Ria. Jurnal Manajemen Pemasaran Petra. Vol. 1, No. 2, hal. 1-7.

Schiffman, L.G \& Kanuk, L.L. 2004. Consumer Behavior. $8^{\text {th }}$ Edition. New Jersey. Prentice Hall.

Sembiring, I. J., Suharyono, dan Kusumawati, A. 2014. Pengaruh Kualitas Produk dan Kualitas Pelayanan terhadap Kepuasan Pelanggan dalam Membentuk Loyalitas Pelanggan (Studi pada Pelanggan McDonald's MT. Haryono Malang). Jurnal Administrasi Bisnis, Vol. 15, No. 1, Oktober 2014, 1-10.

Shah, F. T., Khan, K., Imam, A., Sadiqa, M. 2015. Impact of Service Quality on Customer Satisfaaction of Banking Sector Employee: A Study of Lahore, Punjab. Vidyabharati Interdisciplinary Research Journal. 4(1), 54-60.

Sondakh, C. 2014. Kualitas Layanan, Citra Merek dan Pengaruhnya terhadap Kepuasan Nasabah dan Loyalitas Nasabah Tabungan 
(Studi pada Nasabah Taplus BNI Cabang Manado). Jurnal Riset Bisnis dan Manajemen. Vol. 3, No. 1, 2014, 19-32.

Sugiyono. 2013. Metode Penelitian Manajemen. Cetakan Ke-1. Bandung. Penerbit Alfabeta.

Suhendra, G dan Yulianto, E. 2017. Pengaruh Kualitas Layanan terhadap Nilai Pelanggan dengan Kepuasan sebagai Variabel Mediator. Jurnal Administrasi Bisnis. Vol. 51, No. 2, Oktober, hal. 58-67.

Sunyoto, D. 2014. Dasar-Dasar Manajemen Pemasaran. Jakarta. Center of Academic Publishing Service

Susepti, A, Hamid, D dan Kusumawati, A. 2017. Pengaruh Kualitas Layanan Terhadap Kepuasan dan Loyalitas Tamu Hotel. Jurnal Administrasi Bisnis. Vol. 50, No. 5, September 2017, hal. 27 36.

Tjiptono, F, 2005. Pemasaran Jasa. Malang. Bayumedia.

Toor, A., Hunain, M., Hussain, T., Ali, S., \& Shahid, A. 2016. The Impact of E-Banking on Customer Satisfaction: Evidence from Banking Sector of Pakistan. Journal of Business Administration Research. Vol. 5, No. 2, 27-40.

Tu, Y.T, Li, M.L, \& Chih, H.C, 2013, An Emperical Study of Corporate Brand Image, Customer Perceived Value and Satisfaction on Loyality in Shoes Industry, Journal of Economic and Behavioral Studies, Vol 5 No. 7 (July), 469483.
Windarti, T dan Ibrahim, M. 2017. Pengaruh Kualitas Produk dan Kualitas Pelayanan terhadap Kepuasan Konsumen Produk Donat Madu. Jurnal FISIP. Vol. 4, No.2, 2 Oktober 2017, hal. 110.

Yamit, Z. 2013. Manajemen Kualitas Produk dan Jasa. Yogyakarta. Penerbit Ekonesia.

Zeithaml, V.A, 1988, Consumer Perceptions of Price, Quality, and Value: A Means-End Hipotesis and Synthesis of Evidence, Journal of Marketing, Vol, 52 (July), 2-22. 